\title{
A Evasão Escolar no PRONATEC: a realidade em Cursos de Formação Inicial e Continuada no Instituto Federal de Minas Gerais - Campus Bambuí
}

\author{
Márcia Helena Batista Corrêa da Costa, Flaviane Ribeiro da Costa \\ Universidade do Estado de Minas Gerais, Instituto Federal de Minas Gerais
}

DOI: 10.15628/rbept.2019.5177

Artigo submetido em out/2016 e aceito em ago/2018

\begin{abstract}
RESUMO
A questão da evasão escolar é uma realidade presente em todas as modalidades de ensino e um desafio a ser superado na educação. Pode ser motivada por inúmeros fatores, como a dificuldade do estudante em conciliar trabalho e estudo, a falta de interesse pelos conteúdos escolares, as dificuldades de aprendizagem, a desestruturação familiar, dentre outros. Diante da importância e relevância deste tema, procurou-se compreender, neste trabalho, quais os motivos da evasão escolar no curso de formação inicial e continuada em pedreiro de alvenaria do Pronatec, ofertado na cidade de Bambuí, sob responsabilidade do IFMG. A escolha por este curso justifica-se por ter sido o que apresentou o maior índice dentre os cursos em andamento durante o período da pesquisa. Para isso, além da pesquisa documental e bibliográfica, foram realizadas entrevistas com os gestores, professores e alunos evadidos do curso em questão.
\end{abstract}

Palavras-Chave: Pronatec. Formação inicial e continuada. Evasão.

\section{SCHOOL DROPOUT AT PRONATEC: REALITY IN INITIAL AND CONTINUING EDUCATION COURSES AT THE FEDERAL INSTITUTE OF MINAS GERAIS - CAMPUS BAMBUII}

\begin{abstract}
The issue of school evasion is a present reality in all forms of education and a challenge to be overcome in education. It can be driven by numerous factors, including the student's difficulty in reconciling work and study, lack of interest in school subjects, learning difficulties, family breakdown, among others. Given the importance and relevance of this theme, we tried to understand, in this work, the reasons for school dropout in the initial and continuing masonry training course from the governmental program known as Pronatec - offered in the city of Bambuí, under the responsibility of IFMG. The choice of this course is justified because it was the one with the highest rate among courses in progress during the survey period. Besides documentary and bibliographic research, interviews were conducted with managers, teachers and dropout students from the masonry course.
\end{abstract}

Keywords: Pronatec. Initial and continuing masonry training course. Evasion. 


\section{INTRODUÇÃO}

A questão da evasão escolar é uma realidade presente em todas as modalidades de ensino e um desafio a ser superado na educação. Ela pode ser motivada por inúmeros fatores, tais como a dificuldade do estudante em conciliar trabalho e estudo, a falta de interesse pelos conteúdos escolares, as dificuldades de aprendizagem e a desestruturação familiar, dentre outras.

Sabe-se que esse problema envolve não só o aluno e sua realidade, mas também as instituições de ensino, uma vez que pode estar relacionado também a questões pedagógicas, de infraestrutura da escola e de como o aluno se insere no ambiente escolar.

O Relatório de Desenvolvimento Humano, publicado pelo PNUD em 2012, demonstrou que o Brasil tem a terceira maior taxa de abandono escolar dentre os 100 países com maior IDH. A taxa no Brasil é de 24,3\%, perdendo apenas para a Bósnia Herzegovina (26,8\%) e as ilhas de São Cristovam e Névis, no Caribe (26,5\%) (PNUD, 2012).

Diante do exposto, conclui-se que a evasão é um grave problema no país e que suas causas precisam ser estudadas, a fim de se buscar soluções para o enfrentamento desta realidade.

O abandono escolar é percebido nas mais diferentes modalidades de ensino, apresentando índices ainda mais elevados nos cursos destinados a jovens e adultos. Na maioria dos casos, isso se deve, principalmente, às responsabilidades que eles possuem, já que, em sua maioria, precisam trabalhar para o seu sustento e o de sua família.

No final de 2011, foi criada a Lei oㅜ 12.513, que instituiu o Programa Nacional de Acesso ao Ensino Técnico e Emprego - Pronatec. O grande objetivo deste programa é a interiorização da Educação Profissional, por meio de ações institucionais do Sistema "S", dos Institutos Federais e das Universidades Federais. Além de qualificar, gratuitamente, um público-alvo composto majoritariamente por adultos de baixa renda, o programa fornece bolsa-auxílio no valor médio de $\mathrm{R} \$ 2,00$ por hora/aula ao beneficiário, com o 
objetivo de custear a alimentação e o transporte dos alunos inscritos e frequentes nos cursos oferecidos.

Verifica-se, no entanto, a ocorrência de evasão e de baixa frequência, mesmo que, por meio do programa, sejam criadas condições favoráveis ao aluno, como disponibilidade de bolsas e acesso a material didático gratuito.

Diante da importância e relevância do tema, a questão norteadora desta pesquisa foi a compreensão dos motivos da evasão escolar no curso de formação inicial e continuada em pedreiro de alvenaria do Pronatec, ofertado na cidade de Bambuí, sob a responsabilidade do IFMG.

Para a realização deste trabalho, o conceito de evasão foi entendido como a saída do aluno da escola, antes do término, ou seja, da conclusão do curso. Pretendeu-se, com a realização do estudo, verificar os seguintes aspectos: identificar e analisar os fatores da evasão escolar nos cursos ofertados pelo Pronatec na cidade de Bambuí, no ciclo 2013/2014, e avaliar se os cursos oferecidos nesse período estavam de acordo com a realidade econômica local, Além disso, traçar o perfil socioeconômico dos alunos matriculados e, na perspectiva dos alunos, conhecer os aspectos relacionados à metodologia, currículo, infraestrutura disponível, os benefícios ofertados e as expectativas que os estudantes possuem sobre sua formação profissional.

O estudo também visou a analisar a percepção dos gestores atuantes nos referidos cursos sobre a oferta e o desenvolvimento dos cursos, assim como buscou-se verificar, sob a ótica desses profissionais, os possíveis fatores da evasão escolar.

Os resultados do estudo serão apresentados como alternativa para a busca de soluções que auxiliem no enfrentamento dos problemas relativos à evasão e baixa frequência escolar, no âmbito de atuação do Campus Bambuí do IFMG, responsável pela oferta dos cursos no município. Acredita-se que os resultados da pesquisa desenvolvida na cidade de Bambuí poderão auxiliar também em outras localidades onde são ofertados cursos da mesma natureza via Pronatec. 


\section{EDUCAÇÃO E EVASÃO ESCOLAR}

Estudos mostram que as taxas de evasão escolar têm se apresentado altas. Tanto nos cursos ofertados via Pronatec quanto em outras modalidades de ensino, o problema da evasão escolar pode ser observado e está relacionado a inúmeros fatores. Diante desta realidade, pesquisar este tema torna-se relevante, já que os resultados podem contribuir para a proposição de políticas públicas ou ações voltadas para o enfrentamento do problema. Acredita-se que ações locais planejadas a partir de resultados de estudos e diagnósticos podem ser concebidas para o enfrentamento do problema da evasão.

A evasão prejudica a eficácia dos processos de gestão e afeta o bom desempenho da sociedade em diversos aspectos, tais como o desperdício da capacidade voltada à formação e capacitação, a menor eficiência produtiva das empresas, além da perda da competitividade nacional devido à carência de mão de obra especializada (SILVA FILHO et al., 2007).

Em seus estudos, Neri (2009, p. 46) menciona que "a educação constitui o verdadeiro custo de oportunidade da sociedade - qual seja a alternativa de investimento com maior retorno social disponível". O mesmo autor, em sua pesquisa sobre os motivos da evasão escolar, aponta que, mesmo sabendo dos inúmeros benefícios proporcionados pela educação, o investimento nessa área ainda é pequeno.

Os fatores que levam os alunos à evasão variam muito. Segundo Neri (2009), as três principais motivações são o desconhecimento da política pública por parte dos gestores, a falta de interesse intrínseco dos pais e alunos e, por fim, as restrições de renda e do mercado de crédito que impedem as pessoas de explorar os altos retornos oferecidos pela educação no longo prazo.

Como outros motivos, podem-se enumerar a problemática socioeconômica, as deficiências no processo de alfabetização e o despreparo dos professores. Além disso, frequentemente a escola não motiva os alunos 
nem atrai professores qualificados, ocasionando a evasão e deficiências ao longo do processo ensino-aprendizagem.

O quadro educacional brasileiro é ainda bastante insatisfatório. Sabemos que o problema da evasão e da repetência escolar no País tem sido um dos maiores desafios enfrentados pelas redes de ensino público, pois as causas e consequências da evasão e repetência escolar estão ligadas a fatores sociais, culturais, políticos, econômicos e outros (VIEIRA, 2009, p. 25).

A evasão escolar pode ser ocasionada também pela dificuldade em conciliar trabalho e estudo, pela falta de interesse, pelas dificuldades de aprendizagem e também por situações de desestruturação familiar.

De acordo com Queiroz (2002, p. 1), numa perspectiva social,

o que se observa é que a educação não tem sido plena no que se refere ao alcance de todos os cidadãos, assim como no que se refere à conclusão de todos os níveis de escolaridade. Em seu lugar, o que se vê é que cada vez mais a evasão escolar vem adquirindo espaço nas discussões e reflexões realizadas pelo Estado e pela sociedade civil, em particular pelas organizações e movimentos relacionados à educação no âmbito da pesquisa científica e das políticas públicas.

O problema da evasão envolve não só o aluno e sua realidade, mas também, e principalmente, a escola, devido ao processo de ensinoaprendizagem adotado e as estratégias implementadas para se garantir a permanência dos alunos na escola.

Segundo Abramovay (2003) e Dayrell (2009) apud Silva, Pelissari e Steimbach (2013, p. 405),

no caso específico da educação profissional técnica de nível médio, apesar do significativo aumento na oferta de vagas ocorrido nos últimos anos, tem-se constatado um panorama de expressivo abandono. Há casos em que a taxa de abandono passa de $75 \%$ (BRASIL, 2009), número não raro 
quando se trata da modalidade Proeja ou de qualquer modalidade no período noturno.

A evasão analisada em suas múltiplas facetas precisa ser interpretada considerando-se o fenômeno como parte do que alguns estudiosos chamam de "exclusão escolar", pois a não permanência na escola, motivada pelas condições de vida do educando, expressa também essa exclusão.

De acordo com pesquisa realizada em 2001 pela equipe do Cenpec, entende-se por "exclusão escolar" a impossibilidade de acesso e permanência no sistema de ensino ou o resultado de processos de segregação/diferenciação internos ao sistema escolar. Outros fatores apontados como exclusão de jovens e adultos do processo de escolarização estão relacionados às péssimas condições sociais e econômicas do país, que dificultam o acesso da grande maioria que se vê impossibilitada de estudar e/ou força o abandono precoce dos que conseguem ingressar no sistema escolar formal (VIEIRA, 2009).

Sendo assim, percebe-se a relevância de se contemplar, nas análises, as condições de vida dos alunos, sua trajetória, suas dificuldades cotidianas, suas percepções de mundo - este mundo inclui a forma ou formas sobre como eles concebem a escola e as possibilidades de acesso ao trabalho. Todo esse conjunto de situações interfere na obtenção de êxito nos estudos e no exercício da profissão por parte dos alunos.

\subsection{A escolha do curso do Pronatec}

Quando questionados sobre os motivos que os levaram a se inscrever em um curso do Pronatec, as respostas dos evadidos variaram bastante. Alguns apontaram como principal motivo da escolha a necessidade de aprender a profissão de pedreiro para realizar pequenos trabalhos para eles mesmos e/ou para suas famílias, não estabelecendo, necessariamente, uma relação direta com uma oportunidade de geração de emprego e renda: 
Porque lá em casa, quando eu via as construções, eu não sabia, não entendia, eu queria aprender mais (ALUNO 1).

Aprender pra não depender de ninguém, eu mesma pegar no duro (ALUNO 2).

Eu queria aprender pra fazer pra mim, não para fazer coisas para os outros (ALUNO 3).

Essas respostas indicam a busca de autonomia, mas, ao mesmo tempo, mostram que a questão da profissionalização, para alguns, não representou o fator-chave para a escolha da formação como pedreiro.

As "novas" exigências para o trabalho indicam uma nova condição para o trabalhador, que, de acordo com Machado (1998), pode ser resumida em: "saberem gerir sua própria atividade, seu tempo pessoal e suas capacidades de forma a ser eficiente na resolução de problemas e imprevistos; exercendo "autonomia", tendo em vista o trabalho independente, não submetido à supervisão de outros de modo a tomar decisões adequadas na hora certa, mostrar flexibilidade e disposição para assumir mutações e ritmos variados de trabalho aplicando a criatividade na busca de soluções novas e desenvolver estratégias de contínuo aperfeiçoamento (MACHADO, 1998, apud CARMO, 2005, p. 82).

Outros alunos, que já atuam profissionalmente como pedreiros, relataram ter ingressado no curso para aprimorar seus conhecimentos acerca da profissão. Algumas respostas foram selecionadas:

Pra ver se aprimorava mais, porque eu trabalho de pedreiro faz tempo (ALUNO 6).

Pra poder trabalhar para mim e para os meus irmãos [...] Porque nós trabalhamos como "meia-colher" (ALUNO 4).

Já sei fazer muitas coisas. Eu me matriculei pra profissionalizar (ALUNO 5).

O principal motivo foi esse, pra me profissionalizar, pra ter um certificado (ALUNO 6).

Esses resultados vão ao encontro do art. $2^{\circ}$ da LDB, que indica que

a educação, dever da família e do Estado, inspirada nos princípios de liberdade e nos ideais de solidariedade humana, tem por finalidade o pleno desenvolvimento do educando, seu 
preparo para o exercício da cidadania e sua qualificação para o trabalho (BRASIL, 1996a).

Os depoimentos citados confirmam também uma das finalidades dos Institutos Federais de Educação, Ciência e Tecnologia, que é

ofertar educação profissional e tecnológica, em todos os seus níveis e modalidades, formando e qualificando cidadãos com vistas na atuação profissional nos diversos setores da economia, com ênfase no desenvolvimento socioeconômico local, regional e nacional (BRASIL, 2008).

Neste sentido, é importante observar que alguns participantes da pesquisa trabalham no próprio município.

Percebe-se, também, por meio das afirmações dos participantes, o alcance do objetivo dos Institutos Federais:

ministrar cursos de formação inicial e continuada de trabalhadores, objetivando a capacitação, o aperfeiçoamento, a especialização e a atualização de profissionais, em todos os níveis de escolaridade, nas áreas da educação profissional e tecnológica (BRASIL, 2008).

No entanto, cabe aqui ressaltar que os alunos que participaram da pesquisa são evadidos, não terminaram o curso iniciado e não tiveram acesso à referida certificação profissional, que é o objetivo mais importante no processo da oferta educacional - a formação com êxito.

Ainda sobre a questão da escolha do curso, o professor 1, em sua fala, considera que os alunos optaram pela inscrição em um curso do Pronatec por ser de formação rápida e devido ao fato de a construção civil, no momento em que o curso foi oferecido, estar em fase de crescimento.

O professor 2, ao ser questionado em relação aos motivos que levaram os alunos a se matricularem no curso, considera que eles ficaram envolvidos pela novidade, pela mídia e também pela possibilidade de terem um curso com diploma e, ainda, pelo incentivo de receberem uma verba para estudar, além de material e uniforme.

\subsection{Os principais fatores da evasão}


Vários foram os motivos citados pelos alunos evadidos sobre os fatores do abandono do curso de FIC em pedreiro de alvenaria. Na maioria das vezes, as respostas diferenciaram-se bastante umas das outras, mas algumas foram semelhantes.

Coincidentemente, as alunas entrevistadas responderam que desistiram devido ao retorno, no final do curso, de alguns alunos que estavam infrequentes. Segundo as alunas, como esses alunos não acompanharam as aulas que antecederam a parte prática final, que foi a construção de um muro, elas consideraram que isso provocou uma desordem nesse período.

Os moços que já tinham saído entraram pra fazer bagunça, não pra levantar a coisa certa (ALUNO 2).

Muita gente que começou, que foi em poucas aulas, no fim foi mais pra atrapalhar, porque já nem estava valendo mais o curso pra eles (ALUNO 3).

Esse episódio demonstra que os alunos tinham mais interesse nas aulas práticas, pois se ausentaram durante uma parte das aulas teóricas e, no final, voltaram a ser frequentes no período em que houve a construção do muro pelos discentes do curso.

Uma das entrevistadas mencionou a doença do marido como a principal justificativa para o abandono do curso, junto com a reclamação sobre a falta de materiais para as aulas práticas, que apareceu na maioria das respostas.

A principal causa que eu deixei primeiro foi a doença do meu marido, que chegou até a falecer (ALUNO 1).

Pôde-se observar grande insatisfação dos alunos evadidos em relação à falta de material para as aulas práticas. Desde que iniciaram o curso, eles aguardavam, ansiosos, o momento de colocar em prática a teoria que estavam aprendendo. Entretanto, devido a atrasos decorrentes da burocracia na compras de materiais, somente no final do curso os alunos participaram da construção de um muro, como atividade final da aprendizagem.

Aí eles queriam passar teoria dentro da sala, eu queria mais prática, foi onde eu peguei e desisti (ALUNO 4). 
A dificuldade em material, oferecer material pra gente (ALUNO 1).

De acordo com o gestor 1, o Instituto é responsável pelos bens de consumo, como giz, apostilas, pincel e papel, dentre outros, e também pela contratação de professores. Já a prefeitura arca com os bens de capital, ou seja, sala, datashow, retroprojetor, carteiras, etc. O material específico de formação usado nas aulas, principalmente nas de caráter prático, compõem o conjunto do que é fornecido pelo Programa.

Dificuldade é que não tinha a estrutura adequada para o curso (ALUNO 6).

Observa-se que o oferecimento do curso aconteceu com dificuldades na aquisição de materiais, representando um elemento dificultador para a sua realização, destacando-se o caráter específico de um curso de profissionalização de pedreiros.

Sobre esse assunto, o gestor 1 explica que a compra de material tem de atender aos princípios da licitação. Como esse processo demora cerca de 45 dias, dificulta bastante a realização de um curso de curta duração, como os de FIC. O que o Instituto tem feito para minimizar esse problema são parcerias com empresas e/ou o empréstimo de material, por parte da prefeitura, para ser feito o ressarcimento posteriormente. Tais ações têm como objetivo diminuir o atraso no início dos cursos e, consequentemente, evitar que os alunos já matriculados desistam antes mesmo de as aulas começarem.

Em relação à estrutura oferecida, a sala foi avaliada como adequada, assim como os recursos nela disponíveis.

O cansaço também apareceu como uma das principais motivações da desistência. O acúmulo das atividades profissionais com as obrigações do curso também apareceu como fator de evasão. De acordo com Anzolin e Kreling (2013), a necessidade de trabalhar foi citada como a segunda maior causa de abandono escolar, pelo fato de os estudantes necessitarem trabalhar para ajudar financeiramente suas famílias nas despesas. Esse fato demonstra que os discentes jovens e adultos estão mais vulneráveis à evasão. 
Os alunos alegaram que estava difícil e cansativo conciliar o trabalho e o estudo.

Dificuldade é porque é muito tarde o curso, também não tinha muito tempo e acabava que tinha que correr direto pra ir lá pro IF, porque lá nós estávamos fazendo a aula prática (ALUNO 5).

Todo mundo trabalhava, as meninas chegavam das canas às 18 horas, chegavam nas aulas atrasadas (ALUNO 1).

Por parte dos gestores, as opiniões acerca da evasão foram diferenciadas. Na visão do gestor 1 , o principal motivo da evasão dos cursos do Pronatec é o não-cumprimento do calendário, ou seja, o atraso no início das aulas. Além disso, ele citou as dificuldades enfrentadas pelos alunos em relação às disciplinas, pois muitos alunos encontram-se afastados da escola há bastante tempo.

Diferentemente do gestor 1, os motivos apontados pelo gestor 2 acerca do abandono escolar foram relativos ao perfil dos ingressantes que, como pedreiros, em sua maioria, buscavam aprofundar os conhecimentos que já possuíam. Como o curso era básico, o entrevistado acredita que tenha ocorrido a desmotivação e, por isso, os alunos acabavam desistindo do curso.

Além disso, segundo o mesmo gestor, contribuíram com a evasão a dificuldade na contratação de professores e a diversidade de interesses dos alunos que se matricularam no curso, como o oferecimento de auxílio financeiro, a oportunidade de fazer um curso interessante, o aprimoramento profissional, etc. No entanto, no caso dos alunos pesquisados, estes motivos foram ao encontro das expectativas que possuíam no início do curso.

De acordo com o gestor 3, a causa do abandono escolar foi, principalmente, a falta de afinidade dos alunos com o curso. Ele considera que os alunos se matriculavam sem ter muita clareza a respeito dos objetivos do curso, conforme a fala abaixo:

Então, assim, muitas das vezes o próprio Pronatec ainda precisa desenvolver um programa melhor pra selecionar esse aluno, porque esse aluno, às vezes, ele não sabe o que está querendo, ele já tentou uma coisa, tentou outra e tal, e, assim, não sabe o que ele quer. Aí ele então ouve assim: ah, o curso do Pronatec paga pra eu estudar, então ele vai meio 
no escuro, ele não vai como um aluno do curso técnico, que tem objetivo (GESTOR 3).

O fato de a maioria dos alunos trabalhar durante todo o dia e, à noite, ir para o curso foi o principal motivo apontado como causador da evasão, na visão do professor 1. Ele considera que os alunos chegavam cansados e que isso prejudicou o desempenho, em especial nas aulas práticas, momento de maior exigência de esforço físico.

Acho que a evasão se deu pelo fato dos alunos trabalharem durante todo o dia no serviço pesado e à noite vir estudar. $\mathrm{E}$ essa evasão se deu, principalmente, quando começaram as aulas práticas. Então, a pessoa trabalhava durante o dia e chegava a noite ela ainda tinha que trabalhar. Então, ela esperava que não fosse trabalhar, mas ela tinha que trabalhar pra aprender na prática o serviço de pedreiro (PROFESSOR 1).

$\mathrm{Na}$ visão do professor 2, o principal motivo que levou os alunos à desistência foi o fato de o curso ter sido distribuído em módulos de conteúdo, e um professor dava todas as aulas de uma vez nos quatro horários. Sendo assim, se tivessem colocado dois professores, ou matérias diferentes durante a semana, os alunos teriam ficado mais satisfeitos, visto que, no final dos módulos, sobraram poucos alunos.

Até o momento em que foi realizada a entrevista, segundo o gestor 1 , havia a dificuldade em se produzir, com eficiência, um relatório semanal, já que era feito mensalmente, para que a coordenação tivesse condições de repassar à Setec a situação de frequência dos alunos.

Segundo o gestor 1, também, atrasos no início das aulas podem ocasionar uma evasão antecipada. Os fatores desse problema são variados e vão desde o calendário disponibilizado pelo MEC, que costuma sofrer alterações em suas datas, até a dificuldade na contratação de professores.

Percebeu-se, diante dos resultados das entrevistas, que os gestores possuem opiniões diferentes acerca dos fatores que levaram os alunos a abandonar o curso. Essa é uma questão importante e que merece ser revista, visando à maior interação entre eles, a fim de se pensar em soluções para minimizar o abandono escolar. 


\subsection{Avaliação das aulas e material ofertado}

Os professores são peças-chave para a formação profissional e pessoal dos alunos, pois, além dos conhecimentos teóricos e práticos acerca da área em estudo, podem contribuir para a formação humana dos discentes, levando-os a se tornarem profissionais cidadãos e éticos. Em seus estudos, Claudino (2011, p. 67) mencionou que,

Ciente da impossibilidade da neutralidade na educação, Gramsci salienta a importância da formação do professor como intelectual que supere a condição de "preposto do grupo dominante (GRAMSCI, 2004, p. 21), realizador de um trabalho vivo que viabilize a escola ativa e criadora do "novo humanismo", desenvolvendo a consciência do educando quanto à importância do seu comprometimento na construção de um mundo melhor (MACHADO, 1991, p. 141-142).

Os alunos entrevistados avaliaram positivamente as aulas e o material disponível - no caso, as apostilas. Eles elogiaram bastante as aulas, dizendo que os professores eram comprometidos e estavam sempre dispostos a ajudá-los nas dificuldades, visto que a maioria tinha pouca escolaridade.

O professor era muito bom, ótimo, ele fez tudo pra ajudar a gente (ALUNO 1).

Os professores são excelentes, sabe, são excelentes mesmo (ALUNO 2).

No decorrer das entrevistas, os alunos mencionaram que houve a elaboração de apostilas para dar suporte às aulas. Segundo a maioria, este material era de fácil compreensão e auxiliou bastante na aprendizagem.

Ótima, muito boa, muito explicativa a apostila (ALUNO 3).

Muito bom, teve apostila (ALUNO 4).

Acerca do material disponível para a realização do curso, o gestor 2 informou que os próprios professores elaboraram as apostilas, que foram impressas no Campus Ouro Preto. 


\subsection{Avaliação da infraestrutura disponível}

Este item foi avaliado, em parte, de forma positiva pelos alunos pesquisados, pois a sala de aula e os recursos presentes nela eram satisfatórios. Os evadidos comentaram que sentiram a necessidade de uma construção para a realização das aulas práticas. No final do curso, os alunos participaram da construção de um muro, mas, segundo os que foram entrevistados, não foi suficiente para praticar a teoria ministrada em sala de aula.

A sala de aula foi ali no Combem1, era até boa a sala de aula, tudo arrumadinho (ALUNO 2).

A sala de aula era boa, pra passar só o que ele passava ali, era boa, tava de acordo (ALUNO 3).

Não, laboratório não tinha não (ALUNO 5).

A opinião do professor 1 corrobora com as dos alunos, pois ele também mencionou que a infraestrutura para as aulas práticas deixou a desejar. Já o professor 2 disse que, no início, foi muito difícil, mas, depois de um tempo, a estrutura foi normalizando e, atualmente, está satisfatória.

Cabe observar que, segundo o Guia Pronatec de Cursos FIC elaborado pelo MEC para orientar a oferta dos cursos do Pronatec/BolsaFormação, o direcionamento para o curso de pedreiro de alvenaria do Eixo Tecnológico de Infraestrutura não indica a obrigatoriedade da existência de laboratório para a oferta e realização dos cursos dessa modalidade de ensino, indicando as atividades que o profissional poderá desempenhar, a carga horária (200 h) e a escolaridade mínima exigida (ensino fundamental I incompleto) (BRASIL, 2015).

Além disso, o professor 1 acredita que a falta de investimentos para as aulas práticas pode ter ocorrido, principalmente, pela previsão de oferta única do curso. Ele acredita que, se houvesse o planejamento de serem ofertadas várias turmas, haveria uma maior possibilidade de adquirir infraestrutura.

\footnotetext{
${ }^{1}$ Conselho Municipal do Bem-Estar do Menor. 


\subsection{A importância do auxílio ofertado}

O programa prevê o direito de recebimento, por parte do aluno, de ajuda de custo. A quantia contempla $R \$ 2,00$ por hora/aula de que participam. De acordo com os entrevistados, o pagamento desse auxílio sempre foi feito com atraso.

Quando questionados sobre os benefícios desta bolsa, as opiniões foram diversificadas. Quanto aos alunos, alguns consideraram que 0 benefício, mesmo pago com um pouco de atraso, ajuda a quitar despesas pessoais.

Ajuda, porque já dá pra você pagar uma água, dá pra pagar uma luz (ALUNO 2).

Recebi. Ajuda, ajuda muito. Já serve pra ajudar a gente pagar uma luz, uma água (ALUNO 3).

Outros mencionaram que, em vez de receberem a bolsa, podia ser oferecido um lanche aos alunos, já que muitos vêm direto do trabalho, sem ter tempo para se alimentar antes das aulas.

Eu preferia que não fosse um auxílio, que a gente tivesse uma alimentação (ALUNO 1).

Há, ainda, os que comentaram não ter feito muita diferença o recebimento da bolsa.

Não, pra mim não fez diferença não (ALUNO 5).

Não faz diferença não, é pouco demais, no caso (ALUNO 6).

Na visão do gestor 1, o auxílio contribui para a permanência do aluno, ajudando-o nas despesas decorrentes do curso, mas ressalta que é apenas um complemento, e não um fator primordial para os discentes se interessarem em matricular em permanecer no curso.

Segundo o gestor 1, o processo do benefício ofertado aos alunos funciona da seguinte forma: os discentes recebem a Bolsa-Formação, modalidade de bolsa nos cursos FIC, de acordo com o registro de frequência 
por hora/aula assistida no Sistec feito pelo serviço de apoio do Pronatec no Campus Bambuí.

De acordo com esse registro, o FNDE repassa a verba ao Instituto, que a disponibiliza aos alunos, por meio do setor de Assistência Estudantil. Cabe ressaltar que o processo envolve várias etapas e tarefas que são compartilhadas entre o governo e o Instituto.

\subsection{Aspectos positivos ressaltados pelos gestores em relação à oferta do Pronatec}

Conforme mencionado pelo gestor 1 e pelo gestor 2, o Pronatec trouxe muitas mudanças para o campus. Primeiramente, porque inseriu novos alunos, com um perfil diferenciado dos já existentes, e profissionais dentro da instituição. Além disso, alunos oriundos do Pronatec, cerca de 20 a 30\%, começaram a ingressar nos cursos regulares do Campus Bambuí. Acreditase que muitos desses alunos, até então, viam a escola como algo inacessível.

Ainda, segundo o gestor 1, atualmente o Campus Bambuí oferta ensino técnico e superior. Com o Pronatec, pessoas que não tinham nem o ensino fundamental completo passaram a fazer parte do corpo discente da instituição. Então, foi um público novo que veio para o campus, mostrando à sociedade que a escola é acessível aos mais variados tipos de alunos.

Além dessas vantagens, o Pronatec representa uma novidade para o município, contribuindo para o seu desenvolvimento. Tomando como exemplo o curso de FIC em pedreiro de alvenaria, de acordo com o gestor 1, quando um grupo de pessoas que querem ser pedreiros é capacitado, esses novos profissionais vão participar de empreendimentos que podem resultar em situações novas e benéficas para o desenvolvimento do município.

Conforme o gestor 1 , acontece o aprimoramento profissional e pessoal desses alunos, que vão apresentar um rendimento melhor em vários aspectos. Segundo, porque, para o município, esse aluno formado aprendeu a produzir com mais eficiência uma obra, utilizando técnicas corretas e mais eficientes. Isso pode gerar benefícios de caráter social, econômico e até ambiental, contribuindo para que se alcancem cuidados com a sustentabilidade. 
Corroborando com as afirmativas supracitadas, o gestor 2, pela experiência vivenciada ao lado dos alunos, mencionou que é visível a contribuição da formação dos discentes para o desenvolvimento municipal. Segundo ele, os conhecimentos adquiridos no curso são aplicados no dia a dia do trabalho dos alunos, contribuindo para que a população tenha acesso a serviços de melhor qualidade.

\subsection{Aspectos negativos ressaltados pelos gestores em relação à oferta do Pronatec}

Como era previsto, já que o índice de evasão no curso, objeto deste estudo, foi alto, alguns problemas foram citados pelos gestores no decorrer das entrevistas.

$\mathrm{Na}$ opinião do gestor 1, a instabilidade do calendário divulgado pelo MEC é um dos grandes complicadores do bom andamento dos cursos. $\mathrm{O}$ atraso no início das aulas faz com que muitos alunos desistam antes mesmo de começar. Outra questão apontada pelo gestor 1 é relativa à compra de materiais. Tanto os alunos quanto os gestores reclamaram do atraso dos materiais para a realização das aulas.

Já o gestor 2 e o gestor 3 supõem que a falta de padronização e organização em alguns processos relativos à oferta de cursos do Pronatec colabora para o aumento das dificuldades apresentadas pelo programa. Além disso, o gestor 2 citou a dificuldade na contratação de professores e os atrasos nos pagamentos como pontos negativos do programa.

\section{Considerações Finais}

Programas como o Pronatec, embora se façam necessários e se representem como políticas de governo com propósitos de inclusão social, acabam reproduzindo a lógica estrutural marcada pela existência de duas formas de educação. Uma propedêutica, reservada à elite social, e a outra como educação profissional, direcionada às pessoas com pouca escolaridade, preparadas para a habilitação profissional. 
Observa-se, também, que a formação para a cidadania, exposta nas concepções deste tipo de política, na prática são suplantadas pelo pragmatismo não só do mercado, mas também das instituições responsáveis pela aplicação dos programas. Neste caso, tanto os órgãos das administrações municipais envolvidos na realização dos programas de formação profissional como as instituições responsáveis pelo oferecimento dos cursos atuam com o olhar voltado para a empregabilidade no sentido objetivo de formar para o mercado.

Tal pragmatismo, no entanto, esbarra no despreparo ou descuido com a verificação adequada das demandas deste mercado. Observa-se a carência de entrosamento interinstitucional, envolvendo o município, responsável por indicar a demanda local do mercado, e as instituições formadoras. Esse ingrediente sinaliza a carência de diagnósticos, mas também aponta o descuido com a avaliação de procedimentos, fato que interfere na qualidade das políticas e, conseqüentemente, dos programas, no caso em questão, do Pronatec. Essa questão será tratada nesse texto conclusivo da pesquisa, bem como os resultados do estudo, voltado para análise da situação do curso de FIC em pedreiro de alvenaria, oferecido pelo IFMG.

Os depoimentos dos alunos que abandonaram o curso representam o principal resultado do levantamento empírico realizado. Verificou-se, a partir dos dados resultantes da pesquisa de campo, que os motivos da evasão escolar são muito variados e podem estar relacionados a problemas de ordem individual e pessoal, por parte dos alunos evadidos. Evidencia-se, no entanto, a importância de fatores relacionados a aspectos mais estruturais de ordem social e econômica, tal como se verifica a dificuldade em conciliar o trabalho com os estudos. Evidenciou-se que também interfere na evasão escolar o tempo de duração das aulas. Alguns alunos trabalhadores evadem devido ao cansaço, com dificuldades de permanência em sala de aula depois de cumprimento da jornada de trabalho. Interferem também no abandono do curso a falta de interesse e a dificuldade de assimilação dos conteúdos, pois muitos alunos encontram-se distanciados dos estudos há mais tempo. 
Embora os fatores da evasão exponham as limitações dos alunos, constatou-se que há uma avaliação positiva dos evadidos em relação à atuação docente e também sobre o material didático disponibilizado.

Quanto ao benefício ofertado aos alunos para se manterem em curso, esse aspecto teve avaliações bem diferenciadas, não sendo possível, a partir das respostas, definir até que ponto o auxílio foi determinante para a permanência ou não do aluno no curso.

Por fim, mesmo não concluindo o curso, os alunos evadidos, em sua maioria, tiveram uma percepção positiva do curso e demonstraram interesse em continuar os estudos. Verificou-se que há o reconhecimento, pelos alunos, da necessidade da escolaridade para a melhoria de sua qualificação profissional e de vida, e também para sua possível inserção no mercado de trabalho. É importante salientar que, mesmo abandonando o curso, o contato com a escola serviu de estímulo para a retomada de contato com o universo da educação.

Os depoimentos dos gestores apontam diferentes sugestões de enfrentamento da evasão. Percebe-se o reconhecimento, por parte da gestão escolar, da necessidade de se rever ações, com o objetivo de definir estratégias de enfrentamento do problema da evasão, tendo em vista a análise do processo de ensino e aprendizagem, de acordo com a modalidade do curso ofertado, respeitando a realidade dos alunos ingressantes e as possibilidades de sua permanência. Acredita-se que, nesta análise sobre os motivos da evasão escolar, muitas são as variáveis e responsabilidades a serem compartilhadas, com foco na necessidade de um planejamento, acompanhamento e avaliação da gestão do Pronatec como um programa de qualificação profissional.

Os dados e as análises produzidos por meio da pesquisa coincidem com resultados de estudos de caráter mais amplo, tal como exposto por Vieira (2009). Essa autora relata ser o quadro educacional brasileiro ainda bastante insatisfatório, com problemas de ordem social, econômica, cultura e política, dentre outros, fato que leva os alunos, principalmente os das classes sociais menos favorecidas, ao abandono precoce da escola. 
De acordo com o perfil apresentado dos alunos evadidos, acredita-se que está de acordo com o público a que se destina esta modalidade de curso, ou seja, trabalhadores.

Cabe aqui ressaltar que o propósito inclusivo do programa foi alcançado, o de atender, prioritariamente, a população de baixa renda, destacando-se os beneficiários de programas de transferência de renda e estudantes da rede pública de ensino. No entanto, os problemas relacionados à permanência dos alunos nos cursos se mostram como uma variável que precisa ser considerada no processo de avaliação da eficiência e eficácia dessa política.

A avaliação das políticas públicas deveria ser uma prática valorizada pelas agências e órgãos do governo, com vistas à definição dos ajustes e replanejamentos necessários ao bom desempenho de projetos e programas sociais. Procedimentos de avaliação permitiriam intervenções voltadas para a efetividade da política.

Segundo Carvalho (2003), o sistema das políticas públicas é um processo em fluxo, e não pode ser considerado uma sequência linear de etapas. Diante disso, é importante considerá-las como um processo contínuo de decisões que visam a ajustar e adequar as ações ao seu objeto, promovendo alterações fundamentais que permitam alcançar, com êxito, os objetivos inicialmente propostos.

Em seus estudos, Carvalho (2003, p. 186) menciona que

a avaliação é parte constitutiva do processo da política pública. Ou seja, ela não é unicamente formulação e implementação de ações. A avaliação integra-se a esse processo como atividade permanente que acompanha todas as fases da política pública, desde a identificação do problema da política até a análise das mudanças sociais advindas da intervenção pública.

A avaliação também permitirá que os recursos destinados às políticas públicas sejam melhor empregados e aproveitados. Sobre esse assunto, Chiecheslski (2005) afirma que o aumento da racionalidade das políticas sociais pode ser alcançado medindo-se a eficiência no emprego dos recursos e comprovando a eficácia com que são atingidos os objetivos. Desta forma, a relevância dos processos avaliativos justifica-se pela possibilidade de 
proporcionar informações e interpretações mais apropriadas para instrumentalizar o processo de planejamento, possibilitando escolher as melhores opções dentre os programas e projetos a serem implementados e/ou propiciando avaliar os efeitos produzidos pelos que estão em andamento ou concluídos.

Constatou-se que compõe o universo de aplicação do programa e que, portanto, deveria fazer parte dos processos de sua avaliação como política social, a forma como são definidos os cursos no âmbito local e regional. Os cursos são escolhidos em observância aos dados dos beneficiários de programas sociais desenvolvidos pela Secretaria de Assistência Social do município. Diante disto, verificou-se haver demanda pelo curso de pedreiro de alvenaria, já que muitos dos beneficiários mencionaram ter esse ofício como profissão. Como parte do processo investigativo, verificou-se que, embora existam critérios para definição dos cursos a serem ofertados, caberiam diagnósticos mais cuidados e precisos por parte dos órgãos de governo, para que o programa de fato alcance e atenda a real situação do mercado local e regional no que tange à preparação profissional.

Neste sentido, acredita-se haver carência de estudos e de planejamento mais precisos sobre a realidade econômico-social do município e da região. Acredita-se que, extrapolando a análise apenas da situação de evasão do curso de pedreiro (formação que se enquadra em um tipo de demanda universal), a profissionalização proporcionada pelo Pronatec poderia contribuir melhor com a realidade local, fundamentada em suas potencialidades e demandas, uma vez que a economia da cidade tem forte embasamento na área agropecuária, além da indústria e dos serviços. Neste ponto, o IFMG, como instituição de ensino voltada para interferir no desenvolvimento regional e do Estado, poderia apresentar-se como referência para indicar procedimentos de análise de mercado, bem como para a formulação de metodologias de avaliação de políticas governamentais voltadas para a formação profissional, tal como é o caso do Pronatec. 


\section{REFERÊNCIAS}

ANZOLIN, Ricardo Maximo; KRELING, Wagner Luiz. Análise das causas de evasão escolar nos cursos de aprendizagem profissional de uma unidade do Senai/SC no ano de 2012. e-tech - Tecnologias para Competitividade Industrial, Florianópolis, 3 ed., especial, 2013.

BRASIL. Decreto no 5.478, de 24 de junho de 2005. Institui, no âmbito das instituições federais de educação tecnológica, o Programa de Integração da Educação Profissional ao Ensino Médio na Modalidade de Educação de Jovens e Adultos. Disponível em:

$<$ http://www.planalto.gov.br/ccivil_03/_ato2004-

2006/2005/Decreto/D5478.htm >. Acesso em: 09 ago. 2014.

BRASIL. Decreto no 8.268, de 18 de junho de 2014. Altera o Decreto $\mathrm{n}^{\circ} 5.154$, de 23 de julho de 2004, que regulamenta o $\S 2^{\circ}$ do art. 36 e os arts. 39 a 41 da Lei no 9.394, de 20 de dezembro de 1996. Disponível em: <http://www.planalto.gov.br/ccivil_03/_Ato2011-2014 /2014/Decreto/D8268.htm>. Acesso em: 01 fev. 2014.

BRASIL. Guia Pronatec de Cursos FIC. 2015. Disponível em: <http://pronatec.mec.gov.br/ fic/>. Acesso em: 20 mai. 2015.

BRASIL. Lei no 11.892, de 29 de dezembro de 2008. Institui a Rede Federal de Educação Profissional, Científica e Tecnológica, cria os Institutos Federais de Educação, Ciência e Tecnologia e dá outras providências. Disponível em: <http://www.planalto.gov.br/ccivil_03/_ato2007-2010/2008/lei/l11892.htm>. Acesso em: 02 jul. 2014.

BRASIL. Lei no 12.513, de 26 de outubro de 2011. Institui o Pronatec; altera as Leis no 7.998, de 11 de janeiro de 1990, que regula o Programa do Seguro-Desemprego, o Abono Salarial e institui o FAT; no 8.212 de 24 de julho de 1991, que dispõe sobre a organização da Seguridade Social e institui Plano de Custeio; no 10.260, de 12 de julho de 2001, que dispõe sobre o Fundo de Financiamento ao Estudante do Ensino Superior; e no 11.129 , de 30 de junho de 2005, que institui o ProJovem; e dá outras providências. Disponível em: <http://www. planalto.gov.br/ccivil_03/_ato20112014/2011/lei/l12513.htm>. Acesso em: 12 ago. 2014.

BRASIL. Lei no 9.394, de 20 de dezembro de 1996a. Estabelece as Diretrizes e Bases da Educação Nacional. Diário Oficial [da República Federativa do Brasil], Brasília, v. 134, n. 248, 23 dez. 1996. Seção I, p. 27.834-27.841.

\section{BRASIL. MEC. Referenciais Curriculares Nacionais da Educação}

Profissional de Nível Técnico. 2000. Disponível em:

<portal.mec.gov.br/setec/arquivos/pdf/introduc.pdf>. Acesso em: 23 ago. 2014. 
BRASIL. Parecer no 16/99. Trata das Diretrizes Curriculares Nacionais para a Educação Profissional de Nível Técnico. 1999. Disponível em:

$<$ http://portal.mec.gov.br/setec/ arquivos/pdf/PCNE_CEB16_99.pdf>. Acesso em: 05 ago. 2014.

BRASIL. PNQ. 2003. Disponível em:

<http://www3.mte.gov.br/pnq/conheca_base.pdf>. Acesso em: 13 ago. 2014.

BRASIL. Pronatec. 2014. Disponível em: <http://pronatec.mec.gov.br/fic/>. Acesso em: 07 ago. 2015.

BRASIL. Resolução no 126, de 23 de outubro de 1996b, do Codefat, MTE. Aprova critérios para a utilização de recursos do FAT pela SEFOR, com vistas à execução de ações de qualificação e requalificação profissional, no âmbito do Programa do Seguro-Desemprego, no período de 1997/1999. Disponível em: <http://portal.mte.gov.br/codefat/resolucao-n-126-de-23-101996.htm >. Acesso em: 12 ago.2014

BRASIL. Resolução no 6, de 2012. Define Diretrizes Curriculares Nacionais para a Educação Profissional Técnica de Nível Médio. Diário Oficial da União, Brasília, p. 22-24, 21 set. 2012. Seção 01.

CARMO, Jefferson Carrielo. Trabalho, educação profissional e a classe trabalhadora. Intellectus, São Paulo, n. 4, ano 2, jan./jul. 2005.

CARVALHO, Rejane Gomes; MOREIRA, Eliana Monteiro. Participação e controle social na gestão da política pública de qualificação profissional na Paraíba. In: Encontro Internacional Participação, Democracia e Políticas Públicas: Aproximando Agendas e Agentes, 23 a 25 abr. 2013, Unesp, Araraquara (SP).

CARVALHO, S. N. de. Avaliação de programas sociais: balanço das experiências e contribuição para o debate. São Paulo em Perspectiva, São Paulo, v. 17, n. 3-4, p. 185-197, 2003. Disponível em: <www.scielo.br/pdf/spp/v17n3-4/a19v1734.pdf>. Acesso em: 13 ago. 2014.

CELLARD, A. A análise documental. In: POUPART, J. et al. A pesquisa qualitativa: enfoques epistemológicos e metodológicos. Petrópolis, RJ: Vozes, 2008.

CHIECHESLSKI, Paulo Cesar Santos. Avaliação de programas sociais: abordagens qualitativas e suas limitações. Revista Textos \& Contextos, Porto Alegre, n. 4, ano IV, dez. 2005. Disponível em: <http://revistaseletronicas.pucrs.br/fo/ojs/index.php/fass/article/view/ 1006/786>. Acesso em: 25 set. 2015.

IFMG. 2013. Disponível em: <www.ifmg.edu.br>. Acesso em: 25 mai. 2014.

IFMG. 2014. Disponível em: <www.cefetbambui.edu.br/portal>. Acesso em: 25 mai. 2014. 
IFSC. 2012. Perguntas e respostas sobre o Pronatec. Disponível em: $<$ linkdigital.ifsc.edu.br/ files/Perguntas-e-respostas-sobre-o-Pronatec.pdf>. Acesso em: 22 jul. 2014.

NERI, Marcelo (Coord.). O tempo de permanência na escola e as motivações dos sem-escola. Rio de Janeiro: FGV/IBRE, CPS, 2009.

PNUD. Relatório de desenvolvimento humano. 2012. Disponível em: <www.pnud.org.br>. Acesso em: 13 ago. 2014.

QUEIROZ, Lucilene Domingos. Um estudo sobre evasão escolar: para se pensar na inclusão escolar. Anped, 2002. Disponível em: $<25$ reuniao.anped.org.br/lucileidedomingos queirozt13.rtf $>$. Acesso em: 10 jul.2014.

SILVA FILHO, R. L. L. et al. A evasão no ensino superior brasileiro.

Cadernos de Pesquisa, São Paulo, v. 37, n. 132, p. 41-659, set./dez. 2007. Disponível em: <www.scielo.br/scielo. php?script+sci_arttext\&pid=S010015742007000300007\&Png=pt\&nrm=iso>. Acesso em: 03 jul. 2014.

SILVA, Mônica Ribeiro da; PELISSARI, Lucas Barbosa; STEIMBACH, Allan Andrei. Juventude, escola e trabalho: permanência e abandono na educação profissional técnica de nível médio. Educação e Pesquisa, São Paulo, v. 39, n. 2, p. 403-417, abr./jun. 2013. Disponível em:

<http://www.revistas.usp.br/ep/article/view/58625>. Acesso em: 20 jun. 2014.

SILVA, Roberto Bittencourt. A educação técnica profissional e a Lei do Pronatec. Democratizar, Rio de Janeiro, v. VI, n. 1, jan./jul. 2012.

VIEIRA, E. F. C. Evasão escolar no curso do Programa Nacional de Integração da Educação Profissional com a Educação Básica na modalidade de Educação de Jovens e Adultos (Proeja). 2009. Dissertação de mestrado. Instituto de Agronomia/Programa de Pós-Graduação em Educação Agrícola. UFRRJ, Rio de Janeiro, 2009. 